\title{
Correction to: Toeplitz Extensions in Noncommutative Topology and Mathematical Physics
}

Francesca Arici and Bram Mesland

\section{Correction to:}

Chapter 1 in: P. Kielanowski et al. (eds.), Geometric Methods in Physics XXXVIII, Trends in Mathematics, https://doi.org/10.1007/978-3-030-53305-2_1

The original version of the book was inadvertently published without the following corrections. The chapter has now been corrected.

\section{Corrections:}

Chapter 1, "Toeplitz Extensions in Noncommutative Topology and Mathematical Physics" was mistakenly published non-open access. This has been amended with the license updated to CC BY 4.0 and the Copyright Holder changed to "The Author(s)". The book has also been updated with this change.

Page iv: The corresponding OA information has been included. 